\title{
Selective blockade of CD28 on human T cells facilitates regulation of alloimmune responses
}

\author{
Masaaki Zaitsu, ${ }^{1,2}$ Fadi Issa, ${ }^{1}$ Joanna Hester, ${ }^{1}$ Bernard Vanhove, ${ }^{3,4,5}$ and Kathryn J. Wood \\ ${ }^{1}$ Transplantation Research Immunology Group, Nuffield Department of Surgical Sciences, University of Oxford, John \\ Radcliffe Hospital, Headington, Oxford, United Kingdom. ²Department of Gastroenterological Surgery I, Hokkaido \\ University Graduate School of Medicine, Sapporo, Japan. ${ }^{3}$ Centre de Recherche en Transplantation et Immunologie UMR \\ 1064, INSERM, Université de Nantes, Nantes, France. ${ }^{4}$ Institut de Transplantation Urologie Néphrologie (ITUN), CHU \\ Nantes, Nantes, France. ${ }^{5} \mathrm{OSE}$ Immunotherapeutics, Nantes, France.
}

T cells are central to the detrimental alloresponses that develop in autoimmunity and transplantation, with CD28 costimulatory signals being key to $\mathrm{T}$ cell activation and proliferation. CTLA4-Ig molecules that bind CD80/86 and inhibit CD28 costimulation offer an alternative immunosuppressive treatment, free from some of the chronic toxicities associated with calcineurin inhibition. However, CD80/86 blockade by CTLA4-Ig also results in the loss of coinhibitory CTLA4 signals that are critical to the regulation of $\mathrm{T}$ cell activation. Here, we show that a nonactivating monovalent anti-CD28 that spares CTLA4 signaling is an effective immunosuppressant in a clinically relevant humanized mouse transplant model. We demonstrate that selective CD28 blockade prolongs human skin allograft survival through a mechanism that includes a reduction in the cellular graft infiltrate. Critically, selective CD28 blockade promotes Treg function in vivo and synergizes with adoptive Treg therapy to promote transplant survival. In contrast to CTLA4-Ig treatment, selective CD28 blockade promotes regulation of alloimmune responses and facilitates Treg-based cellular therapy.

Authorship note: $\mathrm{MZ}$ and $\mathrm{FI}$ contributed equally to this work.

Conflict of interest: BV is a shareholder of OSE Immunotherapeutics, a company developing CD28 antagonists.

Submitted: July 6, 2016

Accepted: August 29, 2017

Published: October 5, 2017

Reference information: JCI Insight. 2017;2(19):e89381. https://doi.org/10.1172/jci. insight.89381.

\section{Introduction}

Optimal $\mathrm{T}$ cell activation requires the interaction of $\mathrm{T}$ cell receptors with $\mathrm{MHC}$ antigen-peptide complexes and the engagement of a costimulatory receptor with its respective ligand on a professional antigen-presenting cell (APC). A number of costimulatory molecules influence $\mathrm{T}$ cell activation and proliferation, the best characterized of which are CD28 and the cytotoxic T lymphocyte-associated antigen-4 (CTLA4, CD152). While CD28 signaling is critical for $\mathrm{T}$ cell activation and proliferation, CTLA4 signaling is a coinhibitory molecule that functions to terminate these processes. Both CD28 and CTLA4 share the same ligands, B7-1 (CD80) and B7-2 (CD86), but the avidity of CTLA4 for these ligands is higher compared with that of CD28. The relative ligation of CD28 and CTLA4 on the surface of T cells is, therefore, an important determinant of whether CD28 costimulatory or CTLA4 coinhibitory effects are dominant during an immune response $(1,2)$.

Due to the toxicity associated with the administration of calcineurin inhibitors (3), targeting the CD28/ CD80-86 pathway - with fusion proteins such as CTLA4-Ig, for example - is a promising alternative. However, in clinical trials, an increase in the incidence of acute rejection with CTLA4-Ig treatment compared with cyclosporine standard immunosuppression has been observed (4). In addition, direct CD80/86 blocking strategies inhibit CTLA4 signaling, which is crucial to the function of Tregs, thus impacting the potential development of immunological unresponsiveness (5-7). With the progression of cellular therapies to the clinic, there is a concern regarding the effect CTLA4-Ig would have on Treg therapy for the treatment of immune pathologies, including transplant rejection. Hence, selective blockade of CD28 is theoretically advantageous, as it would preserve the coinhibitory signals delivered upon CTLA4 engagement (8). In this study, we investigate the effects of FR104 - a PEGylated monovalent humanized Fab' antibody fragment antagonist of CD28 (9) - in a humanized mouse transplantation setting, comparing its effects directly with CTLA4-Ig therapy. 
A

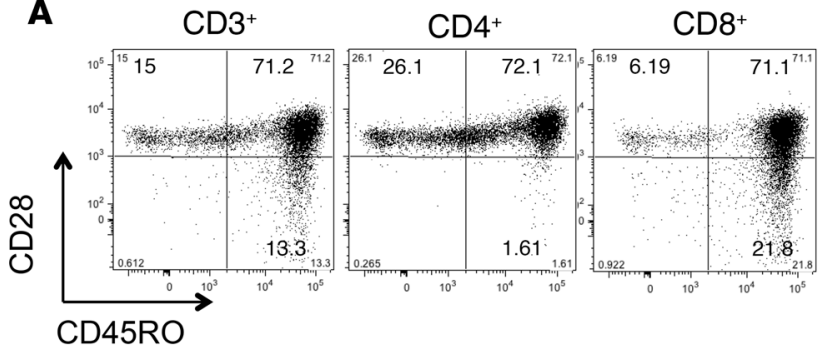

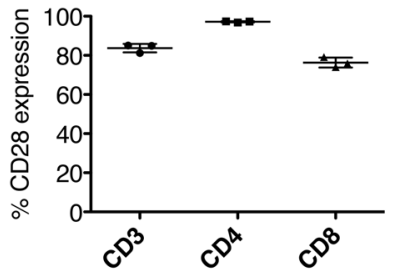

B
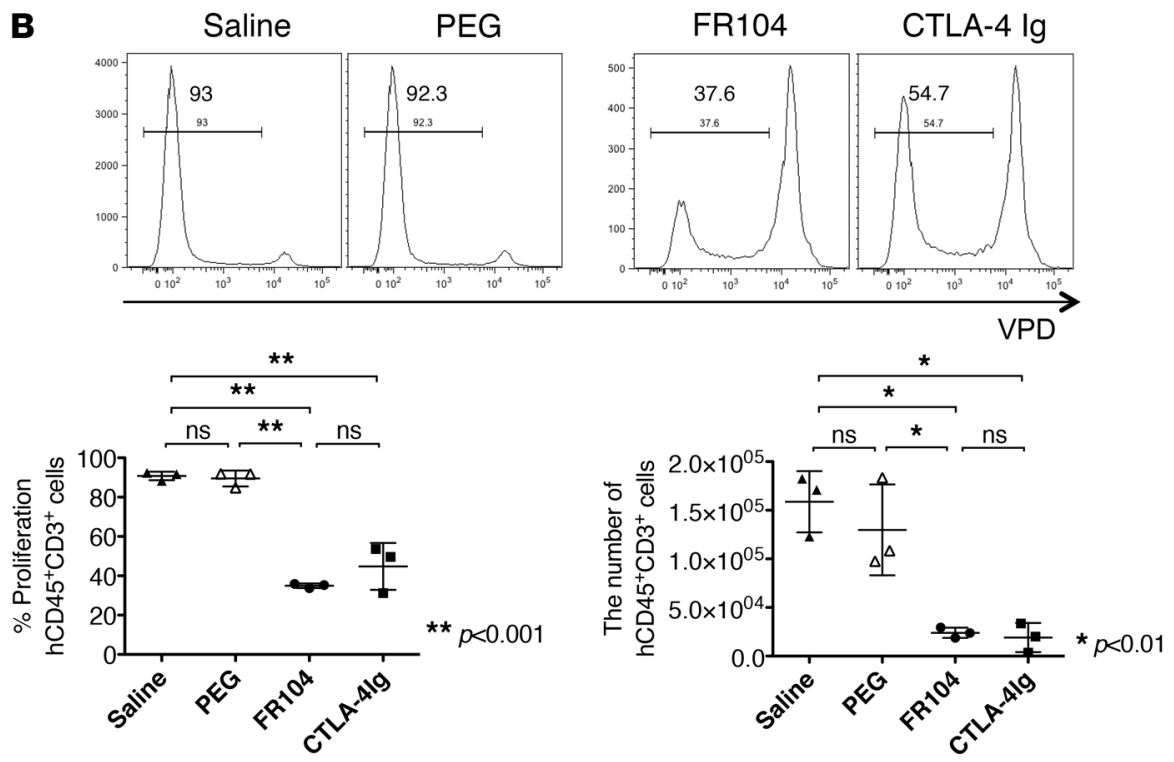

Figure 1. FR104 and CTLA4-Ig inhibit human $\mathrm{T}$ cell proliferation in vivo. Fluorescent-labeled human PBMCs (5 $\times 10^{6}$ ) were adoptively transferred by i.p. injection on day 0 into immunodeficient mice. (A) CD28 expression on human T cells was measured 6 days later $(n=3)$. (B and $\mathbf{C}$ ) Mice were treated on day 1 and day 3 with saline, PEG, FR104, or CTLA4-Ig i.v. $(n=3)$. Peritoneal cells were harvested on day 6 after adoptive transfer. FR104 and CTLA4-Ig significantly inhibited human $T$ cell proliferation and activation in vivo. This assay was repeated 3 times using different human PBMC donors. Data are shown as mean \pm SD. All data were analyzed by one-way ANOVA followed by Tukey's multiple-comparisons test. ${ }^{*} P<0.01,{ }^{* *} P<0.001$.

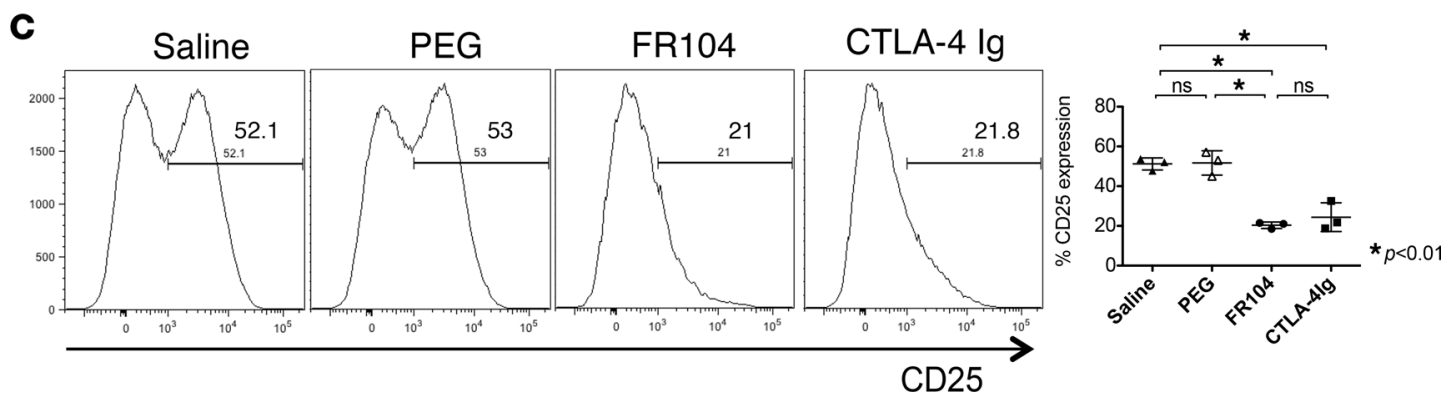

\section{Results}

CD28 expression of human leukocytes in humanized mice. We first evaluated CD28 expression on human leukocytes in BALB/c Rag2 ${ }^{-/} \mathrm{C} \gamma^{-/-}$mice reconstituted with human peripheral blood mononuclear cells (PBMCs). The majority of human $\mathrm{CD}^{+} \mathrm{T}$ lymphocytes expressed CD28 on their surface after adoptive transfer in vivo $(97 \% \pm 0.3 \%, n=3)$, whereas human $\mathrm{CD}^{+} \mathrm{T}$ lymphocytes had a lower expression of CD28 after engraftment $(76 \% \pm 2.1 \%, n=3$, Figure $1 \mathrm{~A})$. CD28- human $\mathrm{CD} 8^{+} \mathrm{T}$ lymphocytes were of a memory phenotype, expressing surface CD45RO.

FR104 and CTLA4-Ig inhibit human leukocyte proliferation in vivo. To examine the effects of FR104 and CTLA4-Ig in vivo, we performed a human leukocyte proliferation assay in humanized mice. Violet proliferation dye-labeled (VPD-labeled) human PBMCs $\left(5 \times 10^{6}\right)$ were transferred into mice by i.p. injection. Mice then received treatment with FR104 or CTLA4-Ig on day 1 and day 3 by i.v. injection. Both FR104 and CTLA4-Ig significantly inhibited the proliferation of human $\mathrm{CD} 45^{+} \mathrm{CD} 3^{+}$leukocytes compared with saline or PEG control groups $(P<0.01)$; no differences were observed between FR104 and CTLA4-Ig treatment groups (Figure 1B). Expression of the activation marker CD25 was reduced in both treatment groups (Figure 1C). We next investigated whether treatment with FR104 or CTLA4-Ig promoted apoptosis, finding that there was no increase in the number of apoptotic cells detected by flow cytometry with drug treatment 
A
Human skin graft
Donor A
$10 \times 10^{6}$ PBMC i.p Donor B

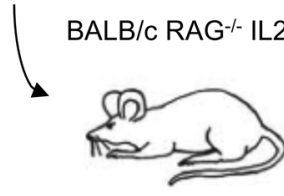

Day -35 Skin transplant

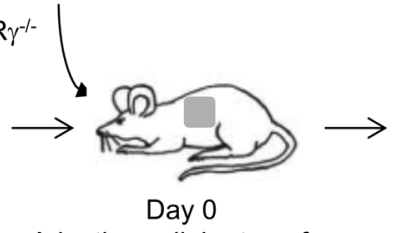

Adoptive cellular transfer

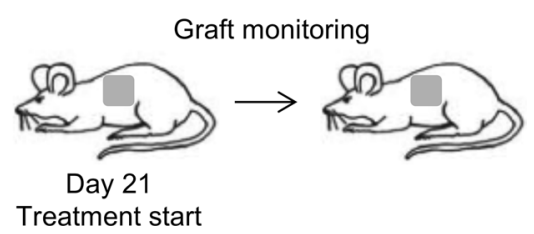

Figure 2. FR104 treatment prolongs human skin allograft survival. (A) Schematic representation of the chimeric humanized mouse model. BALB/c Rag2 ${ }^{-/-} \mathrm{c} \gamma^{-/-}$ mice were transplanted with a human skin graft, which was allowed to heal for 35 days before adoptive transfer of $10 \times 10^{6}$ PBMCs i.p. After confirmation of adequate PBMC engraftment on day 21 after adoptive transfer, groups of mice were treated with saline $(n=5)$, PEG $(n=3)$, FR104 $(n=5)$, or CTLA4-Ig $(n=5)$ i.v. (B) Only FR104 treatment prolonged skin graft survival. (FR104 $1 \mathrm{mg} / \mathrm{kg}$ vs. saline, $P=0.0116$; and FR104 $5 \mathrm{mg} / \mathrm{kg}$ vs. saline, $P=0.0031$; log-rank test). (C) Chimerism levels of human $\mathrm{CD} 45^{+}$cells in the peripheral blood on day 21 and day 28 after adoptive transfer.
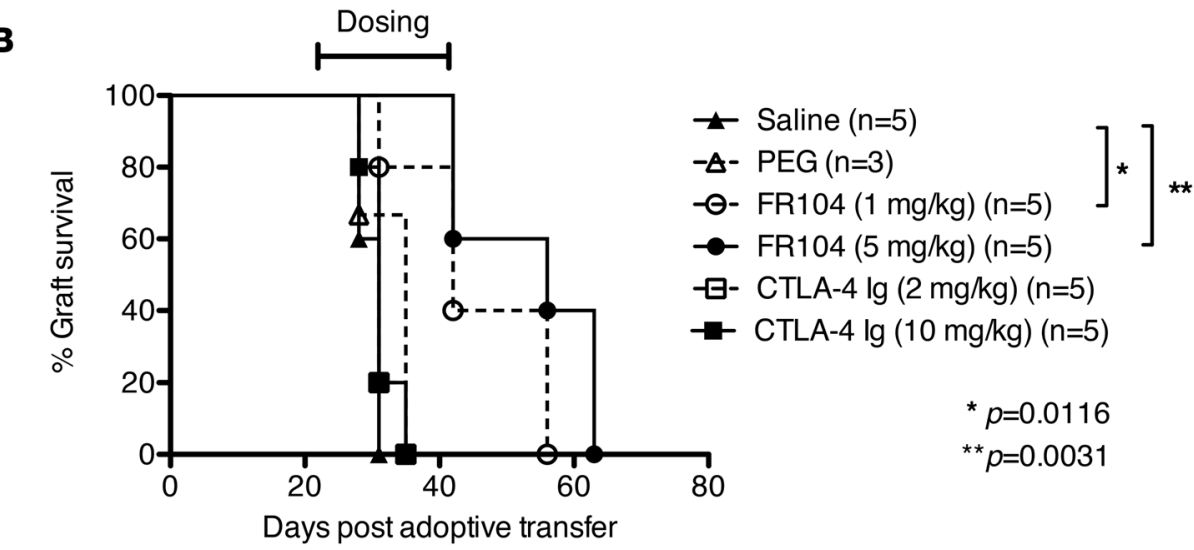

C

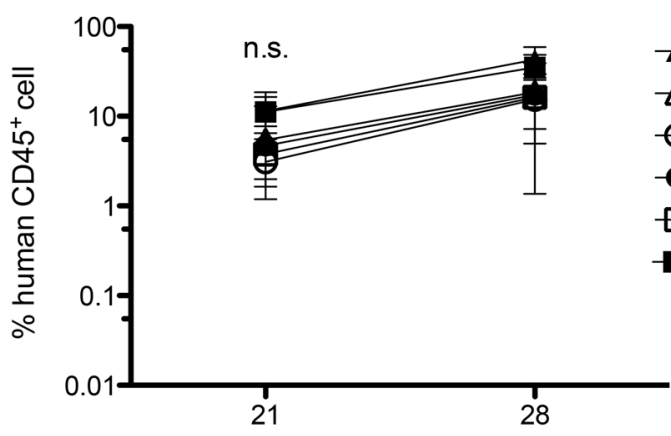

Days post adoptive transfer
- Saline $(\mathrm{n}=5)$
$\triangle \operatorname{PEG}(n=3)$
- FR104 (1 mg/kg) $(\mathrm{n}=5)$
- FR104 (5 mg/kg) (n=5)
曰 CTLA-4 lg $(2 \mathrm{mg} / \mathrm{kg})(\mathrm{n}=5)$
- CTLA-4 lg (10 mg/kg) $(n=5)$

in comparison with controls (Supplemental Figure 1; supplemental material available online with this article; https://doi.org/10.1172/jci.insight.89381DS1).

FR104 prolongs skin graft survival. The ability of FR104 and CTLA4-Ig to prevent human skin transplant rejection in a humanized mouse model was assessed (Figure 2A). We ensured that mice had an adequate level of human leukocyte chimerism in the peripheral blood 3 weeks after PBMC injection before commencing dosing with FR104 or CTLA4-Ig (Figure 2C). Saline and PEG control-treated mice displayed similar human skin allograft rejection kinetics, with median survival of times (MST) of 31 and 35 days, respectively. Surprisingly, low-dose CTLA4-Ig $(2 \mathrm{mg} / \mathrm{kg})$ and high-dose CTLA4-Ig (10 mg/ $\mathrm{kg}$ ) treatments were unable to prolong skin graft survival (MST $=31$ for both doses). By contrast, mice treated with low-dose FR104 (1 mg/kg) and high-dose FR104 (5 mg/kg) displayed significantly enhanced survival of the human skin allograft compared with control groups (MST $=42$ days; $P=0.0116$ and 56 days; $P=0.0031$, respectively, Figure 2B and Table 1). Importantly, these data indicate that FR104 has the capability to abrogate rejection that may already be in progress, as mice commence treatment at a point at which graft-infiltrating cells are already present within the allograft.

FR104 reduces both the cellular graft infiltrate and the serum levels of inflammatory cytokines. To investigate the underlying mechanisms and consequences of FR104 treatment in vivo, we analyzed the number of human leukocytes infiltrating human skin allografts (Figure 3A). In the saline control group, infiltration by human 
A
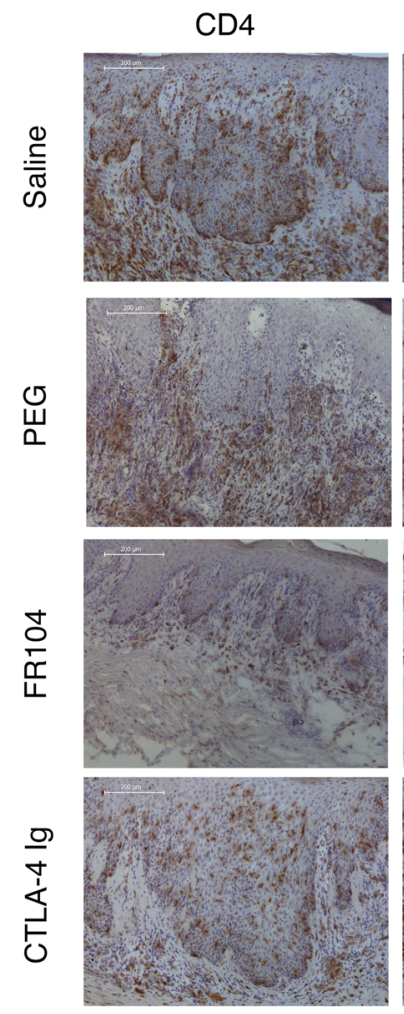

B
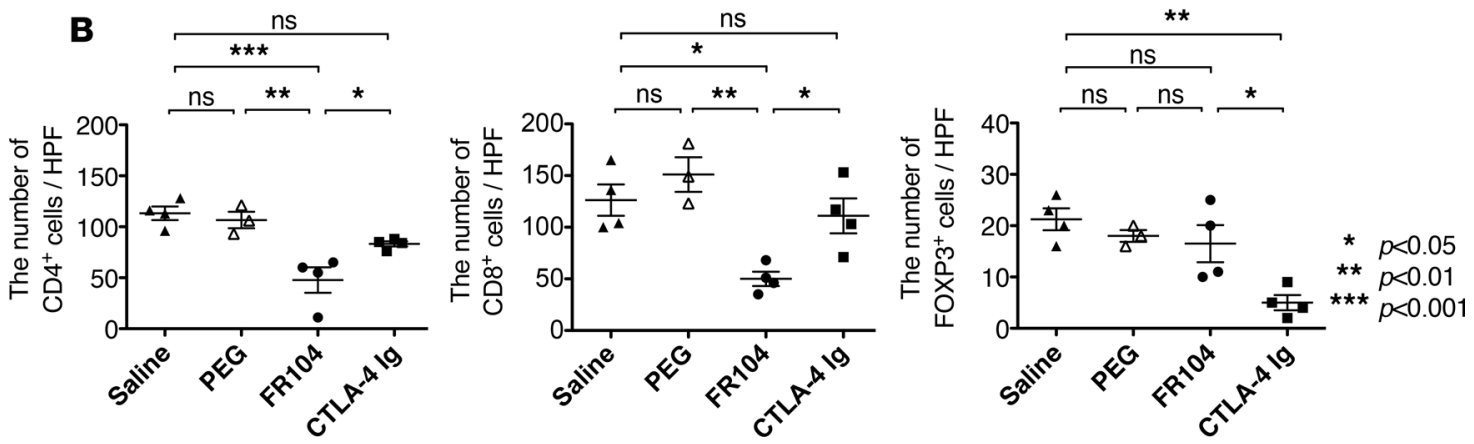

Figure 3. FR104 inhibits the infiltration of human $\mathrm{CD4}^{+}$and $\mathrm{CD8}^{+}$cells, but not FOXP3 ${ }^{+}$cells, into the human skin allograft. (A) Representative photomicrographs (magnification $\times 100$ or $\times 400$ [insets]) of sections from human skin grafts harvested from mice at day 28 after adoptive transfer of human PBMCs. (B) The number of graft-infiltrating human leukocytes at day 28 after adoptive transfer of PBMCs was quantified by IHC for cells stained with CD4, CD8, and FOXP3 in samples from mice treated with saline $(n=4)$, PEC $(n=3)$, FR104 $(n=4)$, or CTLA4-lg $(n=4)$. This assay was repeated 3 times using different human PBMC donors. Data are shown as mean \pm SEM. All data were analyzed by one-way ANOVA followed by Tukey's multiple-comparisons test. ${ }^{*} P<0.05,{ }^{* *} P<0.01,{ }^{* * *} P<0.001$.

$\mathrm{CD}^{+}$and $\mathrm{CD} 8^{+}$cells was almost equivalent (histologic cell count: $114 \pm 10$ for $\mathrm{CD} 4^{+}$vs. $126 \pm 26.4$ for $\mathrm{CD} 8^{+}$cells). The number of graft-infiltrating $\mathrm{CD}^{+}(83 \pm 4.4$ vs. $48 \pm 21.5, P<0.05)$ and $\mathrm{CD} 8^{+}(111 \pm 29.4$ vs. $50 \pm 10.6, P<0.05$ ) cells was significantly reduced by FR104 treatment as compared with CTLA4-Ig. Notably, the number of $\mathrm{FOXP}^{+}$cells was significantly reduced in mice treated with CTLA4-Ig as compared with those treated with FR104 ( $15 \pm 3.6$ vs. $5.0 \pm 1.5, P<0.05$ ) (Figure 3B). We therefore assessed expression levels of skin-homing molecules that may affect the migration of leukocytes into the skin graft. Cutaneous lymphocyte antigen (CLA) and C-C chemokine receptor 4 (CCR4) are key human skin homing molecules $(10,11)$ and have been shown to be important for Treg function in humanized mouse systems $(12,13)$. We found that the majority of $\mathrm{CD} 8^{+} \mathrm{T}$ lymphocytes in the peripheral blood expressed surface CLA 28 days after adoptive transfer and that only FR104 was able to suppress CLA expression $(59 \% \pm$ $10.6 \%$ vs. $8 \% \pm 4.3 \%$, saline vs. FR104, $P<0.01$, Figure 4 A). No differences were seen in the level of CCR4 expression in peripheral blood among treatment groups (Supplemental Figure 2). We next measured inflammatory cytokine levels in the peripheral blood, including IFN $\gamma$, TNF, IL-2, IL-4, IL-6, IL-10, and 
Table 1. Skin graft survival times for each treatment group in Figure 2

\begin{tabular}{lccc}
\hline Group & $\boldsymbol{n}$ & Graft loss days & MST \\
Saline & 5 & $28,28,31,31,31$ & 31 \\
PEG & 3 & $28,35,35$ & 35 \\
FR104 $(1 \mathrm{mg} / \mathrm{kg})$ & 5 & $31,42,42,56,56$ & 42 \\
FR104 $(5 \mathrm{mg} / \mathrm{kg})$ & 5 & $42,42,56,63,63$ & 56 \\
CTLA4-Ig $(2 \mathrm{mg} / \mathrm{kg})$ & 5 & $31,31,31,31,35$ & 31 \\
CTLA4-Ig $(10 \mathrm{mg} / \mathrm{kg})$ & 5 & $28,31,31,31,35$ & 31
\end{tabular}

MST, median of survival times.
IL-17A. In comparison with controls, FR104 inhibited IFN $\gamma$, TNF, IL-2, and IL-10 production. By contrast, CTLA4-Ig did not suppress inflammatory cytokine production (Figure 4B).

FR104 does not adversely impact cellular therapy with Tregs. We have previously demonstrated the ability of ex vivo-expanded human Treg therapy to prevent the rejection of HLA mismatched human vessels (14), skin grafts (15), and islets (16) in vivo. Since FR104 did not inhibit FOXP3 ${ }^{+}$cell infiltration into the allografts, we hypothesized that FR104 would not impact adoptive Treg cellular therapy. We assessed the impact of preincubation of Tregs or conventional $\mathrm{T}$ cells (Tconv) with either FR104 or CTLA4-Ig followed by an in vitro suppression assay. In this assay, preincubation of Tregs with either agent did not have a significant effect on their capacity to mediate suppression of Tconv (Supplemental Figure 6). Interestingly, however, whereas Tconv that were preincubated with FR104 remained responsive to Treg-mediated suppression, those preincubated with CTLA4-Ig were resistant to Treg-mediated suppression $(P<0.0001)$.

To explore this, we performed a Treg proliferation assay in vivo. Immunodeficient mice received $5 \times 10^{6}$ CFSE-labeled PBMCs and $5 \times 10^{6}$ VPD-labeled ex vivo-expanded Tregs. One day later, mice were treated with FR104, CTLA4-Ig, or control, and cells were harvested for analysis on day 4 after adoptive transfer. Both FR104 and CTLA4-Ig inhibited Treg proliferation compared with control groups (Figure 5A). To evaluate Treg function, we next analyzed the effect of FR104 or CTLA4-Ig on the ability of Tregs to suppress CFSE-labeled PBMCs. CTLA4-Ig significantly inhibited CD4 $4^{+} \mathrm{T}$ cell proliferation $(P<0.01)$ but not $\mathrm{CD} 8^{+}$ $\mathrm{T}$ cell proliferation compared with control groups. By contrast, FR104 significantly suppressed CD4 $4^{+} \mathrm{T}$ cell proliferation compared with both control groups and CTLA4- $\operatorname{Ig}(P<0.001$ and $P<0.05$, respectively), and CD8 T cell proliferation compared with control groups $(P<0.01)$ (Figure $5 \mathrm{~B})$. These results indicate that FR104 facilitates Treg function in vivo. Next, we assessed the impact of FR104 on the effect of adoptive Treg cellular therapy in a skin transplantation model. Humanized mice received 10x106 PBMCs together with $5 \times 10^{6}$ ex vivo-expanded Tregs on day 0 . After ensuring adequate human leukocyte chimerism in the peripheral blood on day 21, twice-weekly drug treatment was commenced for 3 weeks (Figure 6, A and C). Mice treated with Treg therapy alone had prolonged skin transplant survival compared with controls (MST $=72$ vs. MST $=34$, respectively; $P=0.0042$ ). Interestingly, the addition of Treg cellular therapy to CTLA4-Ig treatment did not prolong human skin graft survival (CTLA4-Ig vs. CTLA4-Ig + Tregs: MST = 40 vs. MST $=36$, respectively). By contrast, the addition of FR104 to Treg therapy significantly prolonged human skin graft survival beyond that achieved with FR104 treatment alone (MST $>100$ vs. MST $=56$, respectively; $P=0.0269$, Figure $6 \mathrm{~B}$ and Table 2). In an independent assay to assess further whether FR104 has an additive effect on Treg therapy, we assessed the effects of FR104 treatment with subtherapeutic lowdose Treg cell therapy $\left(10 \times 10^{6}\right.$ PBMCs together with $1 \times 10^{6}$ expanded Tregs, Figure 7, A and C). Here, the combination treatment significantly promoted allograft survival when compared with low-dose Treg treatment alone and promoted allograft survival beyond what was achieved using FR104 alone (MST $=89$ vs. $\mathrm{MST}=44, P=0.0021$, Figure 7B and Table 3). CTLA4-Ig did not have this effect. Together, these data demonstrate that CTLA4-Ig treatment impedes Treg cellular therapy, whereas FR104 treatment facilitates and has an additive effect on Treg cellular therapy-induced transplant survival.

\section{Discussion}

The $\mathrm{T}$ cell response is central to rejection following transplantation. $\mathrm{T}$ cell activation is triggered by specific antigen recognition and reinforced by the engagement of costimulation molecules that can regulate $\mathrm{T}$ cell differentiation into either pathogenic effector cells or Tregs. The CD28/CTLA4:B7 pathway is the most well-characterized $\mathrm{T}$ cell costimulatory pathway and is critical for $\mathrm{T}$ cell activation and peripheral tolerance (1, 2, 17-19). Targeting this pathway with CTLA4-Ig is a promising alternative to current immunosuppressive treatments and has found a role in clinical transplantation $(4,20)$. While previous studies have shown that CTLA4-Ig prolongs allograft survival and, in some rodent models, leads to the development of a tolerant state (21-23), nonhuman primate preclinical studies have not been as promising $(5,24-26)$. The reasons for this failure of tolerance promotion might be explained by the possible abrogation of Treg proliferation and function by CTLA4-Ig $(27,28)$. This could be because coinhibitory signals such as CTLA4 are 
A
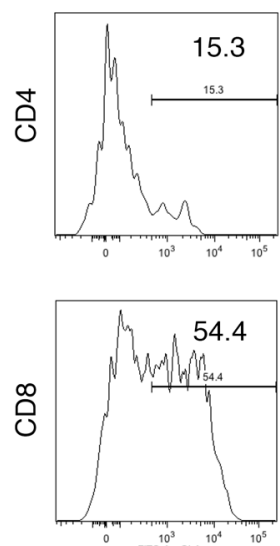

PEG
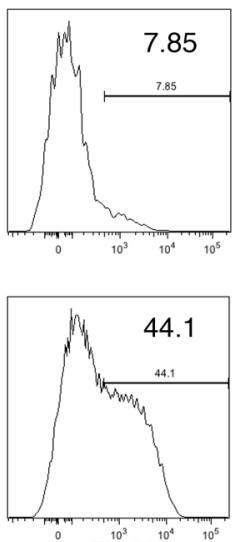

FR104
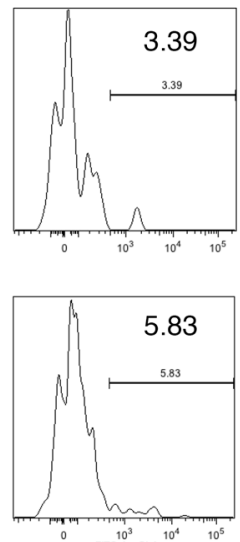

CTLA-4 Ig
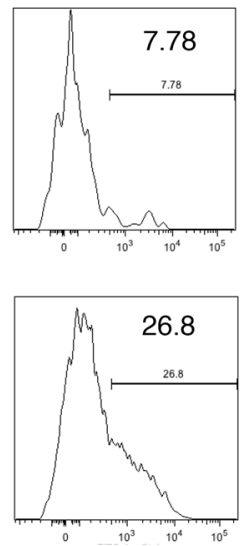

CLA
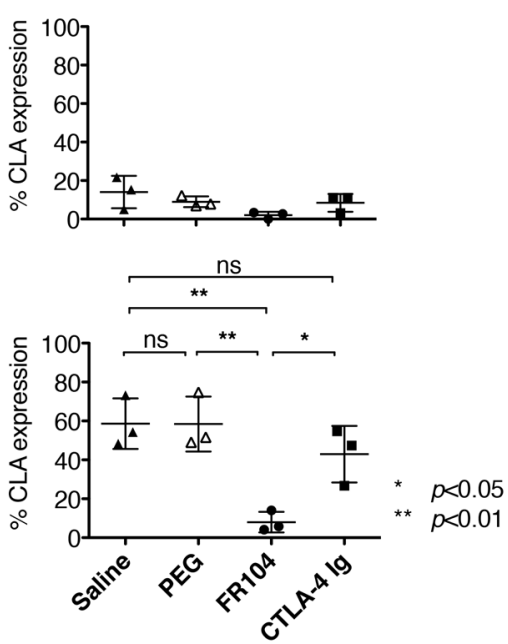

B

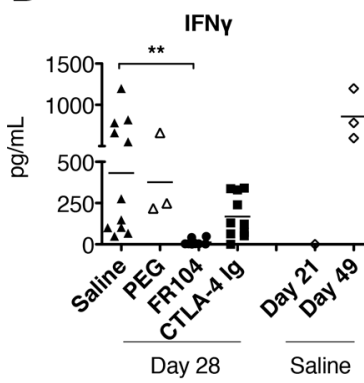

IL-4

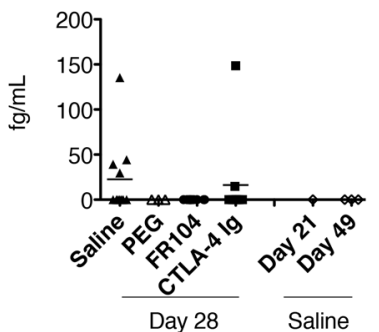

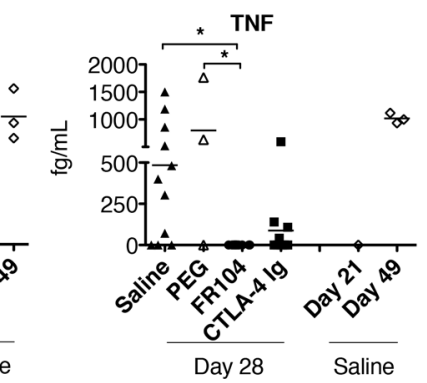

IL-6

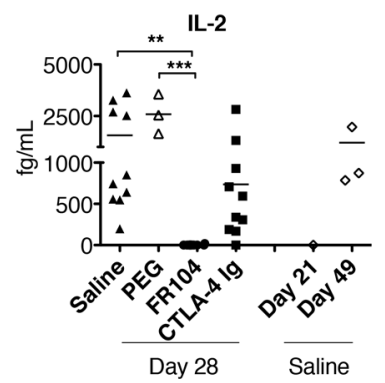

IL-17A

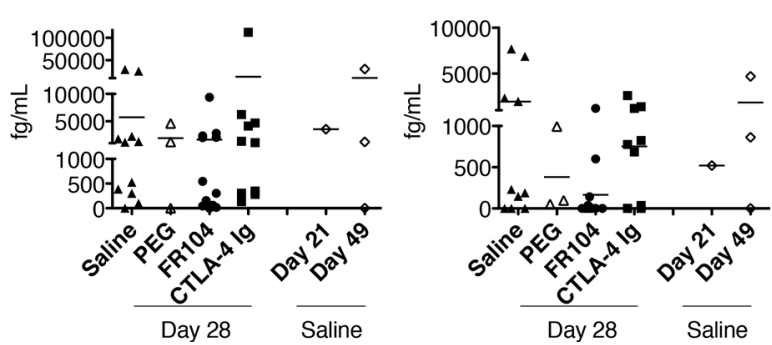

Figure 4. FR104 inhibits CLA expression on CD8 $\mathrm{T}$ lymphocytes as well as inflammatory cytokine production. (A) CLA expression on CD4+ and CD8+ $\mathrm{T}$ cells in the peripheral blood was analyzed by flow cytometry on day 28 after adoptive transfer of PBMCs from mice treated with saline, PEG control, FR104, or CTLA4-Ig $(n=3)$. This assay was repeated twice using different human PBMC donors. (B) Cytokine production in the peripheral blood of mice treated with saline $(n=11)$, PEG $(n=3)$, FR104 $(n=12)$, or CTLA4-Ig $(n=10)$ was assessed using a cytometric bead array. Levels of cytokines in the serum before treatment at day $21(n=1)$ and after treatment with saline at day $49(n=3)$ were also analyzed to provide controls. Data are shown as mean \pm SD. All data were analyzed by one-way ANOVA followed by Tukey's multiple-comparisons test. ${ }^{*} P<0.05,{ }^{* *} P<0.01,{ }^{* *} P<0.001$.

important in promoting the termination of $\mathrm{T}$ cell activation $(29,30)$, and a direct CD80/86 blocking strategy would deprive the evolving immune responses of CTLA4-driven signals. In this study, we have demonstrated a significant difference between a selective CD28 blockade strategy with FR104 and the direct blocking of CD80/86 with CTLA4-Ig in a preclinical transplantation model. It is worth noting that, in this model, human T cells are activated (12) and infiltrate the graft by day 21 after adoptive transfer of human PBMCs (15). FR104 is therefore a powerful immunosuppressant, as it has the capacity to suppress $\mathrm{T}$ cells that are already activated and to rescue a skin graft from rejection after the process has already been set into action. With FR104 now completing a phase I trial in humans, there is genuine promise for its successful introduction in the treatment of a number of immune-mediated pathologies (31).

In this study, the effects of FR104 and CTLA4-Ig in transplanted humanized mice have clear differences. While FR104 and CTLA4-Ig significantly suppress the proliferation and activation of human T cells in vivo to a similar degree, after skin transplantation, there are significant differences in the effects 
A
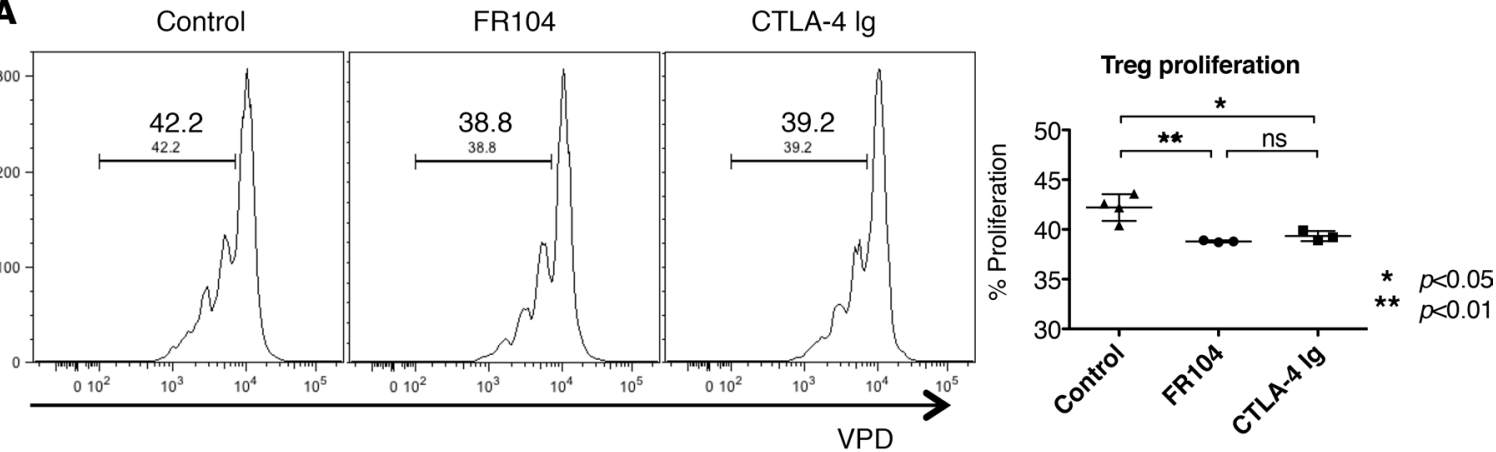

B

Control

FR104

CTLA-4 lg
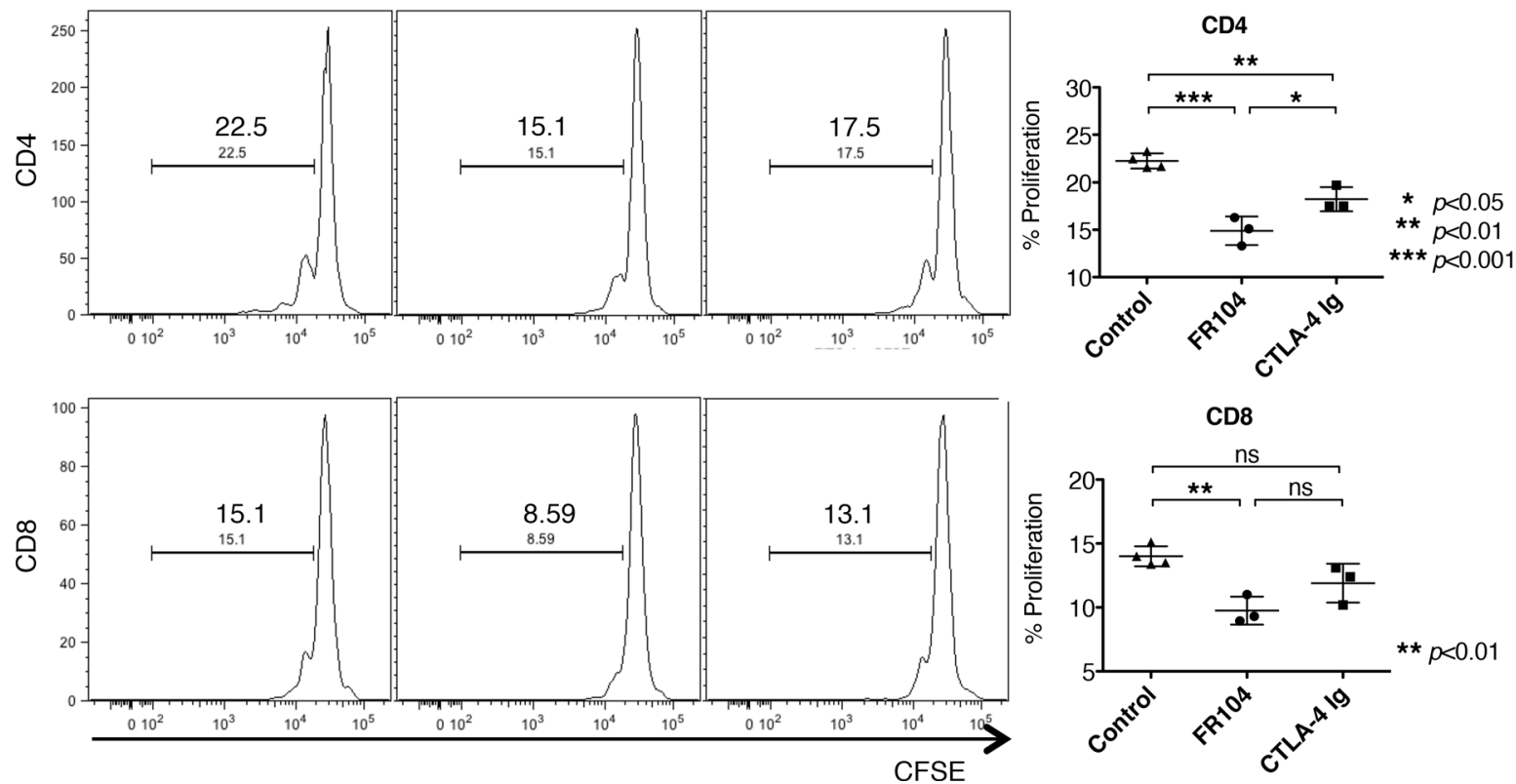

Figure 5. FR104 promotes Treg suppressive activity. BALB/c Rag2 ${ }^{-/-} \mathrm{C} \gamma^{-1-}$ mice received i.p. injections of $5 \times 10^{6} \mathrm{VPD}$-labeled CD127/0 $\mathrm{CD} 25^{+} \mathrm{CD} 4^{+}$cells (Tregs) and $5 \times 10^{6}$ CFSE-labeled PBMC derived from the same donor. Mice were treated with saline or PEC $(n=4)$, FR104 $(n=3)$, or CTLA4-Ig ( $\left.n=3\right)$ on day 1 , and cells were harvested at day 4 after adoptive transfer. (A) FR104 and CTLA4-Ig suppressed the proliferation of CD127 ${ }^{\circ} \mathrm{CD} 25^{+} \mathrm{CD} 4^{+}$cells in vivo. (B) Mice treated with FR104 and Tregs had significantly reduced levels of CFSE-labeled CD4+ and CD8 ${ }^{+} \mathrm{T}$ cell proliferation. Data are shown as mean \pm SD. All data were analyzed by one-way ANOVA followed by Tukey's multiple-comparisons test. ${ }^{*} P<0.05,{ }^{* *} P<0.01,{ }^{* * *} P<0.001$.

of these two agents on the prolongation of skin allograft survival. To exclude the potential confounding effect of blocking human leukocyte repopulation in this model, we confirmed that skin-transplanted mice had attained an adequate level of human leukocyte chimerism before commencing treatment. Not only was CTLA4-Ig inefficient at prolonging graft survival, it was also associated with considerable human $\mathrm{T}$ cell infiltration into the skin allograft. By contrast, FR104 was effective at prolonging human skin allograft survival, and it inhibited human $\mathrm{T}$ cell infiltration into the allograft. Mechanistically, this was partly through the ability of FR104 to reduce the expression level of CLA on T cells. This effect is consistent with a previous study in which the efficacy of FR104 was assessed in a graft-versushost disease (GVHD) model (9). Interestingly, we found that mice treated with FR104 did not have an associated reduction in $\mathrm{FOXP}^{+}$cell infiltration into the allograft compared with control-treated mice, although overall FR104 did inhibit $\mathrm{CD} 4^{+}$and $\mathrm{CD} 8^{+} \mathrm{T}$ cell infiltration into the allograft. While FOXP3 expression alone may not be the most accurate marker of Tregs, its expression - even in activated $\mathrm{T}$ cells - is associated with T cell hyporesponsiveness. Previously, we have shown that Treg treatment prevents rejection and suppresses $\mathrm{CD} 8^{+} \mathrm{T}$ cell infiltration into skin allografts in both mouse-to-mouse and humanized mouse models $(15,32)$. These findings highlight the importance of $\mathrm{CD} 8^{+} \mathrm{T}$ cells in the rejection of skin allografts. In other studies, late treatment with CTLA4-Ig failed to prevent the 
A
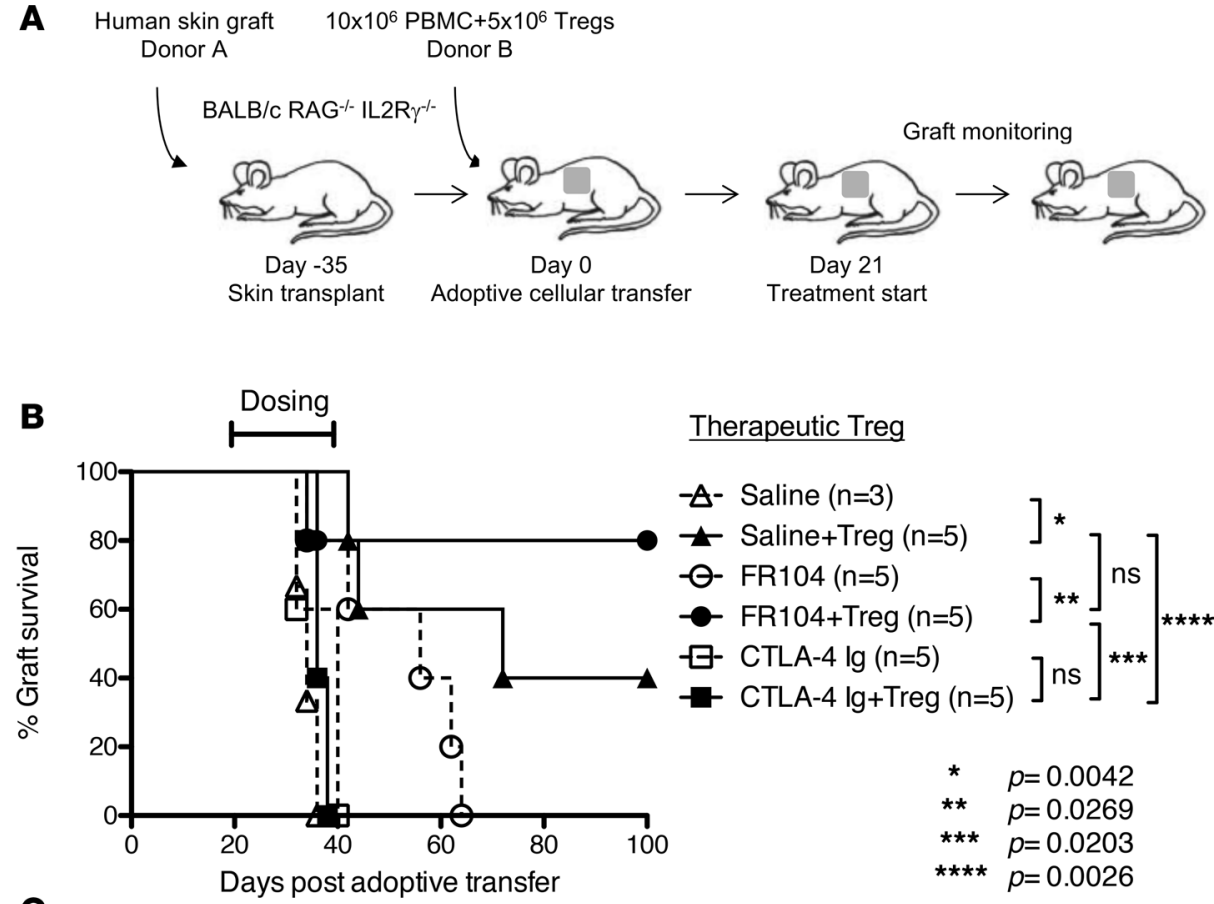

Therapeutic Treg

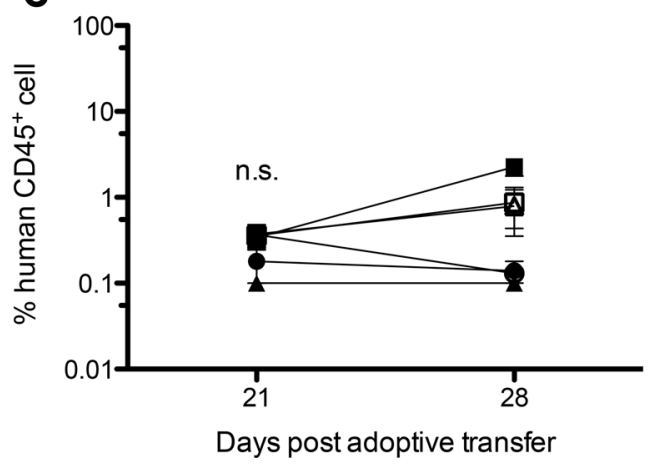

$-A$ - Saline $(n=3)$

- Saline+Treg $(n=5)$

- - FR104 ( $n=5)$

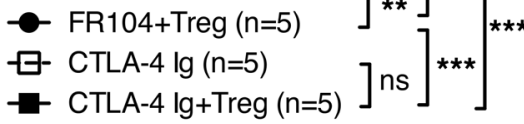

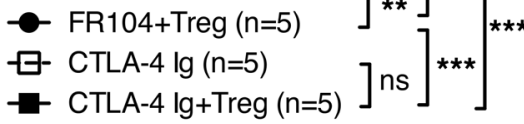

* $p=0.0042$

$\star \star \quad p=0.0269$

$\star \star \star \quad p=0.0203$

$\star \star \star \star ~ p=0.0026$
Figure 6. FR104 treatment does not impede adoptive Treg cellular therapy. (A) Mice received an adoptive transfer of $10 x$ $10^{6}$ PBMCs together with a therapeutic dose of $5 \times 10^{6}$ ex vivo-expanded Tregs and were then treated with saline $(n=5)$, FR104 $(n=$ $5)$, or CTLA4-Ig $(n=5)$. (B) CTLA4-Ig together with Treg treatment did not promote an extension in graft survival compared with CTLA4-Ig alone $(P=0.2338)$. By contrast, FR104 had synergistic effects with Treg cellular therapy, promoting an extension of survival beyond that of Tregs or FR104 alone (FR104 vs. FR104+Treg, $P=0.0269$; Treg vs. FR104+Treg, $P=0.3077$, log-rank test). (C) Chimerism levels of human CD45+ cells in the peripheral blood on day 21 and day 28 after adoptive transfer.

development of diabetes (33) or acute GVHD (34) in mice in which $\mathrm{CD} 8^{+} \mathrm{T}$ cells are pivotal to the pathogenesis. Moreover, Traitanon and colleagues have recently shown that $\mathrm{CD} 8^{+} \mathrm{CD} 28^{-}$memory cells are resistant to CTLA4-Ig treatment (35). These cells may therefore also be resistant to FR104 treatment. In theory, such cells may still receive a coinhibitory signal through CTLA4, making FR104 treatment superior to CTLA4-Ig. We have found that approximately $40 \%$ of $\mathrm{CD} 8^{+}$cells downregulate CD28 expression by day 28 after adoptive transfer (Supplemental Figure 3). Together, these findings suggest that CTLA4-Ig is unable to prolong skin allograft survival due to its inability to act on T cells that are already activated. By contrast, the preservation of coinhibitory signals with FR104 treatment would allow $\mathrm{T}$ cells to reverse their activation status even after they have been activated in vivo. In further support of this, CTLA4-Ig significantly reduced the infiltration of $\mathrm{FOXP}^{+}$cells into skin allografts, whereas FR104 did not.

We also assessed whether FR104 has the ability to facilitate Treg cellular therapy. It has previously been shown that CTLA4-Ig alone has a deleterious effect on Tregs $(27,28)$. Consistent with this, CTLA4-Ig was unable to prolong allograft survival in combination with Treg cellular therapy, an effect that is likely mediated by the inability of Tregs to suppress CTLA4-treated Tconv. By contrast, we found Treg therapy to have synergistic effects with FR104. At therapeutic Treg doses, FR104 did not interfere with Treg-based suppression. At subtherapeutic Treg doses, the combination of FR104 with Treg treatment prolonged allograft survival beyond that achieved with either therapy alone. Here, the direct blockade of CD28 allows Tregs to maintain their suppressive capacity through CTLA4. The assays using combined therapy with FR104 and adoptive transfer of Tregs are critical, given the current proximity of 
Table 2. Skin graft survival times of each treatment group in Figure 6

\begin{tabular}{lccc}
\hline Group & $\boldsymbol{n}$ & Graft loss days & MST \\
Saline & 3 & $32,34,36$ & 34 \\
Saline + Tregs & 5 & $42,44,72,>100,>100$ & 72 \\
FR104 & 5 & $34,42,56,62,64$ & 56 \\
FR104 + Tregs & 5 & $36,>100,>100,>100,>100$ & $>100$ \\
CTLA4-Ig & 5 & $32,32,40,40,40$ & 40 \\
CTLA4-Ig + Tregs & 5 & $34,36,36,38,38$ & 36
\end{tabular}

MST, median of survival times.
Treg therapy to clinical transplantation and the likelihood of its combination with other immunosuppression.

Clinical regulation of allograft rejection by CD28/CD8086 blockade is a promising strategy, and the data in this study support the targeting of this axis in a human context (4). However, although the data presented here are encouraging, they must be interpreted with care. While CD28 selective blockade with FR104 led to a reduction in the graft cellular infiltrate and protected $\mathrm{FOXP}^{+}$cellular infiltration into the skin, only a small number of $\mathrm{FOXP}^{+}$cells infiltrated the skin graft overall. However, in the context of this particular model, we have previously shown that only a very small number of graft-infiltrating FOXP3

cells are sufficient to facilitate graft prolongation in a skin retransplantation assay (13). It is important to bear in mind that there are controversial findings regarding the function of Tregs in the absence of CD28 signals. Zhang and colleagues have demonstrated that Treg-specific CD28 conditional KO mice develop severe autoimmunity and that CD28-deficient Tregs lose suppressive function (36). Conversely, Poirier and colleagues have shown that selective blockade of CD28 costimulation promotes Treg suppression in a nonhuman primate model (37). Ville and colleagues have also shown that FR104 prevents acute rejection, in contrast to CTLA4-Ig, by controlling CD4 T cell follicular helper cells in a nonhuman primate model (38). In a separate mouse study, Zhang and colleagues have shown that selective CD28 blockade using a

A Human skin graft
Donor A $\begin{gathered}10 \times 10^{6} \mathrm{PBMC}+1 \times 10^{6} \text { Tregs } \\ \text { Donor B }\end{gathered}$

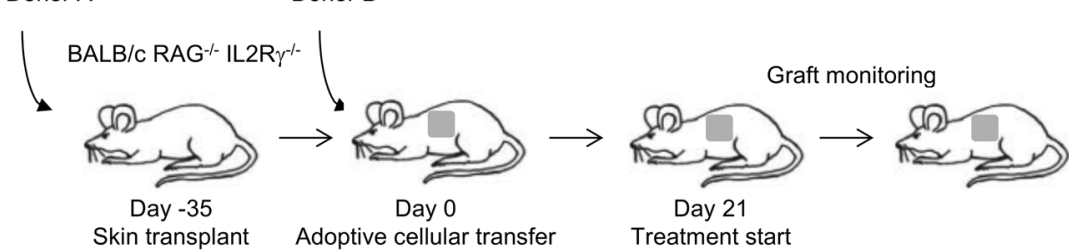

Skin transplant

Adoptive cellular transfer

Treatment start

B

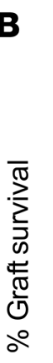

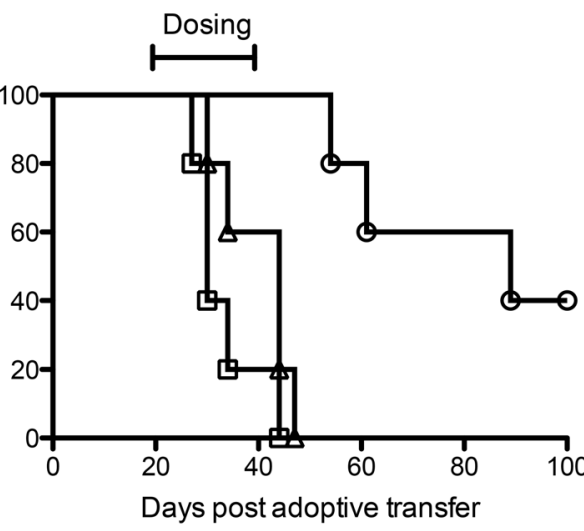

C cellular therapy prolongs human skin allograft survival. (A) Mice received an adoptive transfer of $10 \times 10^{6}$ PBMCs together with a subtherapeutic dose of $1 \times 10^{6}$ ex vivo-expanded Tregs and were then treated with saline $(n=5)$, FR104 $(n=5)$, or CTLA4-Ig $(n=5)$ i.v. (B) FR104 together with the low-dose Treg cellular therapy promoted an extension in skin graft survival compared with subtherapeutic-dose Tregs alone (median of survival times $[\mathrm{MST}]=89 \mathrm{vs}$. MST $=44, P=0.0021$, log-rank test). (C) Chimerism levels of human CD45 ${ }^{+}$cells in the peripheral blood on day 21 and day 28 after adoptive transfer.

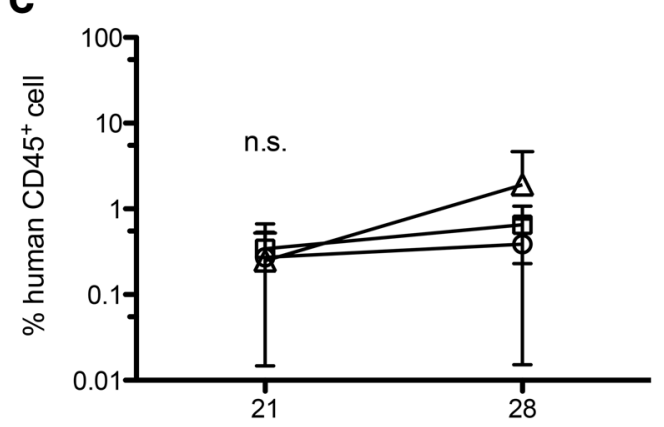

Days post adoptive transfer

\section{Subtherapeutic Treg}

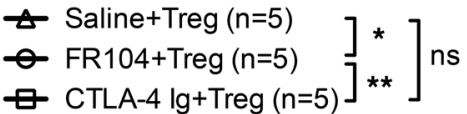

* $P=0.0021$

** $P=0.0018$ 
Table 3. Skin graft survival times of each treatment group in Figure 7

\begin{tabular}{lccc}
\hline Group & $\boldsymbol{n}$ & Graft loss days & MST \\
Saline + Tregs & 5 & $30,34,44,44,47$ & 44 \\
FR104 + Tregs & 5 & $54,61,89,>100,>100$ & 89 \\
CTLA4-Ig + Tregs & 5 & $27,30,30,34,44$ & 30
\end{tabular}

MST, median of survival times. single chain (variable fragment-based) Fv-based reagent leads to a CTLA4-dependent immunomodulation through an increase in Treg infiltration into the graft (39). In our model, given that Tregs were rarely detected in the peripheral blood or allograft in control-treated mice, the principal effect of FR104 is likely to be the suppression of effector $\mathrm{T}$ cell activity and the skewing of the effector/Treg balance. As a combination therapy, FR104 with Treg cellular therapy is a promising strategy for future clinical use, particularly with the majority of other immunosuppressants displaying a propensity to reduce Treg activity and survival (40).

In conclusion, the selective blockade of CD28 costimulation during the activation of $\mathrm{T}$ cells reduces the inflammatory graft infiltrate and alone prolongs human skin allograft survival. Selective blockade does not impact adoptive Treg cellular therapy and may promote a synergism between the two. In this model, where T cells are globally activated, selective CD28 costimulation blockade with FR104 is a more effective immunosuppressant than CTLA4-Ig.

\section{Methods}

Mice. BALB/c Rag2 $2^{-/-} \mathrm{C}^{-1-}\left(\mathrm{H} 2^{\mathrm{d}}\right)$ mice were maintained under specific pathogen-free conditions in the Biomedical Services Unit of the University of Oxford (Oxford, United Kingdom). Mice were aged between 6 and 12 weeks at the time of the first experimental procedure. All mice commenced the treatment regimen 3 weeks after adoptive transfer of allogeneic human PBMCs to ensure adequate levels of human leukocyte chimerism of more than $0.1 \%$ of human $\mathrm{CD} 45^{+}$leukocytes in the peripheral blood.

Skin grafting and treatment protocol. Human skin transplantation was performed as previously described $(15,41)$; briefly, a $1 \mathrm{~cm} \times 1 \mathrm{~cm}$ piece of mouse skin was removed from the dorsal thorax over the costal margin, and then a $1 \mathrm{~cm} \times 1 \mathrm{~cm}$ piece of human skin was sutured to the mouse recipient skin with nonabsorbable 8-0 polypropylene (Ethicon). Grafts were covered with a povidone-iodine mesh and pressure dressing and secured with circumferential tape. Bandages were left in place for 5-7 days and then removed. Skin grafts were allowed to heal for 35 days before adoptive transfer of $10 \times 10^{6}$ human PBMCs i.p. After confirmation of adequate PBMC engraftment (defined as $>0.1 \%$ human CD45 cell chimerism in peripheral blood) on day 21 after adoptive transfer, groups of mice were treated i.v. with $5 \mathrm{mg} / \mathrm{kg}$ FR104 monovalent Fab' fragment (Effimune/OSA Immunotherapeutics) (9), 10 mg/kg CTLA4-Ig (Belatacept, Bristol Meyers Squibb), PEG alone, or saline twice a week for 3 weeks. Skin grafts were monitored regularly until complete loss. In this humanized mouse skin transplant model, the number of HLA mismatches had no impact on overall rejection median survival times (Supplemental Figure 4), and there was no significant variability in engraftment according to the human PBMC donor (Supplemental Figure 5).

Procurement of human PBMC and expansion of human CD127 Tregs. Fresh human buffy coats or leukocyte cones from healthy donors were obtained from the NHSBT (NHS Blood and Transplant), and PBMCs were isolated using standard Ficoll separation techniques. PBMCs were obtained from random donors, and data were pooled. Isolation and expansion of Tregs was performed as previously described $(13,15)$. In brief, CD25+ cells were enriched from PBMC using CD25 microbeads (Miltenyi Biotec); then, $\mathrm{CD} 127^{1 \circ} \mathrm{CD} 25^{+} \mathrm{CD} 4^{+}$cells were sorted using a BD FACSAria cell sorter, using $\alpha \mathrm{CD} 127-$ PE, $\alpha \mathrm{CD} 25-\mathrm{PE}-\mathrm{Cy} 7$ (catalogs 557938 and 335789, respectively; BD Biosciences), and $\alpha \mathrm{CD} 4-\mathrm{ECD}$ (6604727, Beckman Coulter) antibodies. Cells were subsequently expanded in vitro with 1,000 U/ml of recombinant human IL-2 (rhIL-2) (Prometheus Laboratories Inc.) and $\alpha$ CD3/ $\alpha$ CD28 beads $(11131 \mathrm{D}$, Invitrogen) in a 1:3 (first round) and 1:1 (second round) cell/beads ratio over two 7-day rounds, followed by 2 days of silencing in a reduced amount of rhIL-2 after removal of $\alpha \mathrm{CD} 3 / \alpha \mathrm{CD} 28$.

Flow cytometry. For phenotypic analyses, $\alpha \mathrm{CD} 3$-eFluor450 (48-0037-42, eBioscience), $\alpha \mathrm{CD} 4-\mathrm{ECD}$

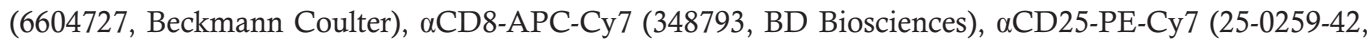
eBioscience), $\alpha \mathrm{CD} 28-\mathrm{PE}$ (555729, BD Biosciences), $\alpha \mathrm{CD} 45-\mathrm{APC}$ (MHCD4505, Invitrogen), $\alpha \mathrm{CD} 45 \mathrm{RO}-$ PE-Cy7 (25-0457-42, eBioscience), and $\alpha$-CLA-FITC (555947, BD Biosciences) were used. 7-AAD viability staining solution (00-6993-50, eBioscience) was used to eliminate dead cells from the analysis. Apoptosis was assessed by Annexin V (BMS147FI, eBioscience)/7-AAD staining.

Cytometric beads array. IL-2, IL-4, IL-6, IL-10, IL-17A, TNF, and IFN $\gamma$ were assessed by a cytometric bead array kit with Enhanced Sensitivity Flex Set System (Quantitation range of 0.274-200 pg/ml) 
(560484, BD Biosciences) according to manufacturer's instructions on serum samples harvested from mice transplanted with a skin graft and reconstituted with allogenic PBMC. No significant differences were detected between saline and PEG controls for any examined cytokines.

In vivo proliferation assay. BALB/c Rag2 $2^{-/-} \mathrm{C} \gamma^{-/-}$mice received $5 \times 10^{6}$ cryopreserved and thawed PBMC labeled with VPD (562158, BD Biosciences) i.p. Treatment was given on day 1 and day 3 , and cells were extracted by peritoneal lavage at day 6 after adoptive transfer. To assess Treg proliferation, mice were injected with $5 \times 10^{6}$ VPD-labeled $\mathrm{CD} 127^{\mathrm{lo}} \mathrm{CD} 25^{+} \mathrm{CD} 4^{+}$cells and $5 \times 10^{6}$ the CFSE-labeled PBMCs from the same donor i.p. Mice were treated on day 1, and cells harvested on day 4 after adoptive transfer.

In vitro proliferation assay. Human PBMCs were labelled with VPD. PBMCs or ex vivo-expanded human Tregs were preincubated with either CTLA4-Ig or FR104 and then used in in vitro suppression assays, as previously described (15), in the absence of inhibitors. The degree of cellular proliferation, ICOS, CD25, and CD39 expression were assessed by flow cytometry.

Tissue typing. Donor blood was analyzed at the Oxford Transplant Centre Histocompatibility Laboratory for HLA-A, -B, -CW, -DR, and -DQ haplotypes.

$I H C$. IHC was performed as previously described $(13,15)$. Briefly, snap-frozen specimens were sectioned at $10 \mu \mathrm{m}$ and stained using biotinylated human antigen-specific antibodies (eBioscience) and an avidin-biotinylated enzyme complex (PK-7200, VECTASTAIN ABC Elite, Vector Laboratories), followed by hematoxylin counter staining. For infiltrating cell quantification, positive cells were counted at $400 \times$ magnification in three random fields of four separate sections for each antibody type. Cell counting was performed in a blinded manner.

Statistics. All statistical analyses were conducted using GraphPad Prism software (GraphPad Software Inc.). Cell numbers and percentages of cell populations were analyzed using one-way ANOVA with Tukey's multiple comparisons test. Survival data were analyzed using the log-rank test. $P$ values of under 0.05 were taken as statistically significant.

Study approval. All experiments in this study were performed using protocols approved by the Committee on Animal Care and Ethical Review at the University of Oxford and in accordance with the UK Animals (Scientific Procedures) Act 1986. Procurement of human tissue samples was performed with full informed written consent and ethical approval from the Oxfordshire Research Ethics Committee, study number 07/H0605/130.

\section{Author contributions}

$\mathrm{MZ}, \mathrm{FI}, \mathrm{JH}$, and KJW conceived and designed the experiments. MZ, FI, and JH performed the experiments. MZ, FI, and JH analyzed the data. MZ, FI, BV, and KJW contributed reagents, materials, and analysis tools. MZ, FI, JH, and KJW wrote the paper.

\section{Acknowledgments}

We would like to thank Tim Goodacre and the staff and patients of the Department of Plastic and Reconstructive Surgery at the John Radcliffe Hospital for assistance with the procurement of skin, K. Milward and S. Shankar for assistance with in vivo assays, the Biomedical Services Unit for expert animal care, the Oxford Transplant Centre for molecular HLA typing, and A. Bushell for his invaluable advice. The work was supported in part by TRIAD FP7-281493, KRUK SF1/2014, the NIHR, Wellcome Trust Programme Grant 082519/Z/07/Z, an Academy of Medical Sciences Sister Grant for Clinical Lecturers, and the Restore Research Trust.

Address correspondence to: Fadi Issa, Transplantation Research Immunology Group, Nuffield Department of Surgical Sciences, University of Oxford, Level 6, John Radcliffe Hospital, Headington, Oxford, OX3 9DU, United Kingdom. Phone: 44.0.1865.222508; Email: fadi.issa@nds.ox.ac.uk.

1. Sayegh MH, Turka LA. The role of T-cell costimulatory activation pathways in transplant rejection. N Engl J Med. 1998;338 (25):1813-1821.

2. Sharpe AH, Freeman GJ. The B7-CD28 superfamily. Nat Rev Immunol. 2002;2 (2):116-126.

3. Nankivell BJ, Borrows RJ, Fung CL, O'Connell PJ, Allen RD, Chapman JR. The natural history of chronic allograft nephropathy. N Engl J Med. 2003;349(24):2326-2333. 
4. Vincenti F, et al. A phase III study of belatacept-based immunosuppression regimens versus cyclosporine in renal transplant recipients (BENEFIT study). Am J Transplant. 2010;10 (3):535-546.

5. Kirk AD, et al. Induction therapy with monoclonal antibodies specific for CD80 and CD86 delays the onset of acute renal allograft rejection in non-human primates. Transplantation. 2001;72 (3):377-384.

6. Haanstra KG, et al. Prevention of kidney allograft rejection using anti-CD40 and anti-CD86 in primates. Transplantation. 2003;75 (5):637-643.

7. Dilek N, et al. Targeting CD28, CTLA-4 and PD-L1 costimulation differentially controls immune synapses and function of human regulatory and conventional T-cells. PLoS One. 2013;8 (12):e83139.

8. Esensten JH, Helou YA, Chopra G, Weiss A, Bluestone JA. CD28 Costimulation: From Mechanism to Therapy. Immunity. 2016;44 (5):973-988.

9. Poirier N, et al. Preclinical efficacy and immunological safety of FR104, an antagonist anti-CD28 monovalent Fab' antibody. Am J Transplant. 2012;12 (10):2630-2640.

10. Clark RA, et al. The vast majority of CLA+ T cells are resident in normal skin. J Immunol. 2006;176(7):4431-4439.

11. Hirahara K, Liu L, Clark RA, Yamanaka K, Fuhlbrigge RC, Kupper TS. The majority of human peripheral blood CD4+CD25highFoxp3+ regulatory T cells bear functional skin-homing receptors. J Immunol. 2006;177 (7):4488-4494.

12. Ali N, et al. Xenogeneic graft-versus-host-disease in NOD-scid IL-2R $\gamma$ null mice display a T-effector memory phenotype. $P L o S$ One. 2012;7 (8):e44219.

13. Issa F, Hester J, Milward K, Wood KJ. Homing of regulatory T cells to human skin is important for the prevention of alloimmune-mediated pathology in an in vivo cellular therapy model. PLoS One. 2012;7 (12):e53331.

14. Nadig SN, et al. In vivo prevention of transplant arteriosclerosis by ex vivo-expanded human regulatory T cells. Nat Med. 2010;16 (7):809-813.

15. Issa F, Hester J, Goto R, Nadig SN, Goodacre TE, Wood K. Ex vivo-expanded human regulatory T cells prevent the rejection of skin allografts in a humanized mouse model. Transplantation. 2010;90 (12):1321-1327.

16. Wu DC, et al. Ex vivo expanded human regulatory $\mathrm{T}$ cells can prolong survival of a human islet allograft in a humanized mouse model. Transplantation. 2013;96 (8):707-716

17. Coyle AJ, Gutierrez-Ramos JC. The expanding B7 superfamily: increasing complexity in costimulatory signals regulating T cell function. Nat Immunol. 2001;2 (3):203-209.

18. Salomon B, Bluestone JA. Complexities of CD28/B7: CTLA-4 costimulatory pathways in autoimmunity and transplantation. Annu Rev Immunol. 2001;19:225-252.

19. Rothstein DM, Sayegh MH. T-cell costimulatory pathways in allograft rejection and tolerance. Immunol Rev. 2003;196:85-108

20. Linsley PS, Nadler SG. The clinical utility of inhibiting CD28-mediated costimulation. Immunol Rev. 2009;229 (1):307-321.

21. Lenschow DJ, et al. Long-term survival of xenogeneic pancreatic islet grafts induced by CTLA41g. Science. 1992;257 (5071):789-792.

22. Turka LA, et al. T-cell activation by the CD28 ligand B7 is required for cardiac allograft rejection in vivo. Proc Natl Acad Sci USA. 1992;89 (22):11102-11105.

23. Pearson TC, Alexander DZ, Winn KJ, Linsley PS, Lowry RP, Larsen CP. Transplantation tolerance induced by CTLA4-Ig. Transplantation. 1994;57(12):1701-1706.

24. Kirk AD, et al. CTLA4-Ig and anti-CD40 ligand prevent renal allograft rejection in primates. Proc Natl Acad Sci USA. 1997;94(16):8789-8794.

25. Levisetti MG, et al. Immunosuppressive effects of human CTLA4Ig in a non-human primate model of allogeneic pancreatic islet transplantation. J Immunol. 1997;159(11):5187-5191.

26. Krieger NR, et al. Prolongation of cardiac graft survival with anti-CD4Ig plus hCTLA4Ig in primates. J Surg Res. $1998 ; 76$ (2):174-178

27. Riella LV, et al. Deleterious effect of CTLA4-Ig on a Treg-dependent transplant model. Am J Transplant. 2012 ;12 (4):846-855.

28. Levitsky J, Miller J, Huang X, Chandrasekaran D, Chen L, Mathew JM. Inhibitory effects of belatacept on allospecific regulatory T-cell generation in humans. Transplantation. 2013;96 (8):689-696.

29. Linsley PS, Brady W, Urnes M, Grosmaire LS, Damle NK, Ledbetter JA. CTLA-4 is a second receptor for the B cell activation antigen B7. J Exp Med. 1991;174 (3):561-569.

30. Tan $\mathrm{P}$, et al. Induction of alloantigen-specific hyporesponsiveness in human $\mathrm{T}$ lymphocytes by blocking interaction of CD28 with its natural ligand B7/BB1. J Exp Med. 1993;177 (1):165-173.

31. Poirier N, et al. FR104, an antagonist anti-CD28 monovalent fab' antibody, prevents alloimmunization and allows calcineurin inhibitor minimization in nonhuman primate renal allograft. Am J Transplant. 2015;15 (1):88-100.

32. Carvalho-Gaspar M, Jones ND, Luo S, Martin L, Brook MO, Wood KJ. Location and time-dependent control of rejection by regulatory T cells culminates in a failure to generate memory T cells. J Immunol. 2008;180 (10):6640-6648.

33. Lenschow DJ, et al. Differential effects of anti-B7-1 and anti-B7-2 monoclonal antibody treatment on the development of diabetes in the nonobese diabetic mouse. J Exp Med. 1995;181 (3):1145-1155.

34. Via CS, Rus V, Nguyen P, Linsley P, Gause WC. Differential effect of CTLA4Ig on murine graft-versus-host disease (GVHD) development: CTLA4Ig prevents both acute and chronic GVHD development but reverses only chronic GVHD. J Immunol. 1996; 157 (9):4258-4267.

35. Traitanon O, et al. IL-15 induces alloreactive CD28 (-) memory CD8 T cell proliferation and CTLA4-Ig resistant memory CD8 T cell activation. Am J Transplant. 2014;14 (6):1277-1289.

36. Zhang R, Huynh A, Whitcher G, Chang J, Maltzman JS, Turka LA. An obligate cell-intrinsic function for CD28 in Tregs. J Clin Invest. 2013;123 (2):580-593.

37. Poirier N, et al. Inducing CTLA-4-dependent immune regulation by selective CD28 blockade promotes regulatory T cells in organ transplantation. Sci Transl Med. 2010;2 (17):17ra10.

38. Ville S, et al. Anti-CD28 Antibody and Belatacept Exert Differential Effects on Mechanisms of Renal Allograft Rejection. $J$ Am Soc Nephrol. 2016;27 (12):3577-3588

39. Zhang T, et al. Selective CD28 blockade attenuates acute and chronic rejection of murine cardiac allografts in a CTLA-4-depen- 
dent manner. Am J Transplant. 2011;11 (8):1599-1609.

40. De Serres SA, Sayegh MH, Najafian N. Immunosuppressive drugs and Tregs: a critical evaluation! Clin J Am Soc Nephrol. 2009;4 (10):1661-1669

41. Milward K, Issa F, Hester J, Figueroa-Tentori D, Madrigal A, Wood KJ. Multiple unit pooled umbilical cord blood is a viable source of therapeutic regulatory T cells. Transplantation. 2013;95 (1):85-93. 